\title{
Evaluation of Oral Health Status and the Need of Surgical and Therapeutical Preprosthodontic measures in the Elderly Living in Old People`s Homes in Latvia
}

\author{
Aldis Vidzis*, Ingrida Krasta**, Anda Brinkmane**, Ingrida Cema*** \\ * Riga Stradins University, Department of Prosthodontics, Latvia \\ ** Riga Stradins University, Department of Therapeutical Dentistry, Latvia \\ *** Riga Stradins University, Department of Oral Pathology, Latvia
}

\begin{abstract}
Summary
Introduction. Demographic evolution indicates enlargement of the older people proportion and increased life expectancy. The oral health is strongly associated with quality of life. In 1992 the main part of Latvian dental care was excluded from the list of the government paid health service. The rules N. 254 (2006) of the Cabinet of Ministers of the Republic of Latvia establish that customers from social old people's homes have to pay for dental care by themselves and the government will prepay only teeth extractions in cases of acute pain. Thereby, there appeared necessity to conduct comparative evaluation of clinical situation among populations of Latvia and other countries.

Aim of the study. The aim of the study was to establish necessary types and ranges of surgical and therapeutical measures before prosthodontical teeth replacement among people who live in old people's homes; to conduct comparative analysis of clinical situation with corresponding groups of age in Latvian population.

Materials and methods. There were examined 212 elderly people living in old people s homes of Kurzeme region of Latvia (randomly chosen). The indices of bad odour were established by HALIMETER. Caries incidence was assessed with DMFT index (D-decayed, M-missing, F-filling). This study was done in period from November of 2007 to February of 2009.

Results. Out of all examined elderly people living in old people s homes $32.3 \%$ of men and $57.3 \%$ of women had complete teeth loss. Caries incidence ratio was 28.7 and 28.8, respectively. Untreated dental caries and filling rate were low $(4.5 ; 2.6$ and 0.6 ; 0.7 ) while the number of lost teeth was high (23.1 and 25.8). Out of the examined elderly $85.7 \%$ of men and $76.5 \%$ of women needed emergency surgical treatment (extraction of destroyed teeth). In $45.2 \%$ and $57.8 \%$ of cases were observed oral mucosal lesions, in $2.4 \%$ and $1.6 \%$ of cases were found oral precancerous conditions. In $14.3 \%$ and $18.8 \%$ of cases was noted pain in temporomandibular joints. $97.6 \%$ and $87.5 \%$ of old people`s homes inhabitants needed prosthodontical teeth replacement.

Conclusions. Oral health care measures for the elderly in old people's homes is insufficient, the ratio of decayed and missing teeth is high, oral hygiene mostly is unsatisfactory and many of them have halitosis. The elderly from old people's homes need vast surgical and therapeutical treatment prior to prosthetics and teeth replacement. The prevalent type of prosthodontics is complete removable dentures. There is need to develop the oral health care conception for the elderly living in old people`s homes in Latvia.

Key words: dental care in old people`s homes, oral surgery, dentistry, prosthodontics.
\end{abstract}

\section{INTRODUCTION}

Demographic evolution indicates enlargement of the older people proportion and increased life expectancy. Different oral health conditions such as carious teeth and their complications, untreated roots in the oral cavity, oral mucosal lesions, precancerous conditions, cancers, pain in the temporomandibular joints, xerostomia, unrestored complete or partial teeth loss affect the quality of life. Physiological and social aspects are very important in the given situation. The typical feature of the elderly is contradiction between the subjective treatment requirements and the objective treatment needs. The social aspects are in base of the social support pattern, those are associated with oral health and wellbeing, as well as, social support and satisfaction of population.

In the 1992 the main part of dental care in Latvia was excluded from the list of the government paid health service. The rules N. 254 (2006) of the Cabinet of Ministers of the Republic of Latvia establish that customers from social old people's homes have to pay for dental care by themselves and the government will prepay only teeth extractions in cases of acute pain. Epidemiologic investigations in numerous countries in the world demonstrate that oral health and dental care of older people are unsatisfactory. WHO researches revealed characterizing parameters of oral health (DMFT index) range from 22 to 32 in developed countries (10). DMFT indices are: in USA - 21.9 (23), in Australia 24.7 (19), in Turkey - 29.3 (21), in Brazil - 30.17 (13), in Fiji - 23 (4). In Latvia oral health of the elderly has been evaluated in 1993 in the project of ICS-2 $(2,22)$. In the 1996 the mean DMFT index in the group of 65 74 years of age in Latvian population was 24.9 (3). In the research in 2005 (3) this index was 24.84 .

In the ICS-2 report (1996) was observed that in Latvia in age group of $65-7495.33 \%$ of people have dentures (22). In Latvian population the necessity 
of new dentures is $60.4 \%(15,14)$. Each country has own experience how to attract investments for health care and to maintain and to effectively promote the state of health of population. The pattern of health care in every country depends on traditions, historical evolution of state and the role of the government in the adjustment in social care $(10,11)$. An evaluation of oral health status in Latvian inhabitants (population of 60- 70 age groups) didn't reveal any information about surgical and therapeutical pretreatment measures before prosthodontic dental care in people who live in social old people's homes.

\section{AIM OF THE STUDY}

The aim of the study was to establish necessary types and ranges of surgical and therapeutical measures before prosthodontical teeth replacement among people who live in old people's homes; to conduct comparative analysis of clinical situation with corresponding groups of age in Latvian population.

\section{MATERIALS AND METHODS}

There were examined 212 randomly chosen elderly people living in old people`s homes of Kurzeme region of Latvia. The examinations were done by dentists worked following unified requirements using dental equipment. The indices of bad odour were established by HALIMETER (Interscan Corporation, Chastworth, California, USA). Caries incidence was assessed with DMFT index (D-decayed, M-missing, F-filling). Oral hygiene was evaluated by Silness \& Loe (1964) plaque index. In the study were examinated and evaluated the dental status, the need of replacement of missing teeth by dentures and indicators of the quality of existing dentures; incidence of pain in head and face region, precancerous conditions and oral mucosal lesions. For this purpose was used standard inquiry form. This study was done in the period from November 2007 to February 2009. For assessment of study results was used descriptive statistics. The acquired data was processed by Microsoft Excel.

\section{RESULTS}

Out of all the examined elderly people living in old people`s homes $32.3 \%$ of men and $57.3 \%$ of women had complete teeth loss. $67.7 \%$ and $42.7 \%$ of them respectively had partial teeth loss and the dental status was assessed as marginal. The caries incidence characterized rate (DMFT index) in people living in old people`s homes was 28.7 and 28.8 , respectively. Untreated dental caries and filling rate were low $(4.5 ; 2.6$ and $0.6 ; 0.7)$ while the number of lost teeth was high (23.1 and 25.8). The lost teeth ratio indicated the multitude loss of teeth (in the average this population have only 2 to 5 residual teeth). The examination revealed that in the average of $58.0 \%$ of cases these teeth should be extracted due to medical indications. From all the examined elderly $85.7 \%$ of men and $76.5 \%$ of women needed emergency surgical treatment (extraction of destroyed teeth). Old people from old people`s homes receive dental care in dental clinics only in acute emergency situations because in Latvia local dental care does not exist for this group of population.
From the elderly with partial teeth loss $45.2 \%$ of men and $57.8 \%$ of women were observed oral mucosal lesions (Fig. 1.), while from old people with complete teeth loss oral mucosal lesions were found in $35.0 \%$ and $45.3 \%$ cases respectively (Fig. 2.). The most common oral mucosal conditions were coated tongue $(26.0 \%)$, erythematous oral mucosa $(24.0 \%)$, atrophic oral and lips mucosa $(14.0 \%)$, denture stomatitis $(12.0 \%)$, varices $(12.0 \%)$, local hyperplasia $(10.0 \%)$, hemangiomas $(12.0 \%)$, angular cheilitis $(8.0 \%)$, actinic cheilitis $(4.0 \%)$, lichen planus $(2.0 \%)$. Several oral mucosal lesions were found in $32.0 \%$. Angular cheilitis, hyperkeratosis at the commissures, white coating on the mucosa and papillary hyperplasia on the palate, erythematous oral mucosa and complaints about dry mouth indicate potential candidiasis in oral cavity.

From all the examined old people with partial teeth loss $26.2 \%$ and $50.0 \%$ of them (men/women) had complaints about dry mouth (Fig. 1.) (suspicion of xerostomia). For the elderly with total teeth loss (Fig.2.) this ratio was $30.0 \%$ and $46.5 \%$, respectively. In $2.4 \%$ and $1.6 \%$ of all older people with retained teeth were found out precancerous conditions such as lichen planus and leukoplakia. In the group of totally edentulous old people precancerous lesions were not found (Fig.1. and Fig 2.). This difference is associated with chronical traumatization of oral mucosa by sharp edges of decayed teeth and roots. The pain in temporomandibular joints (TMJ) was detected in $14.3 \%$ and $18.8 \%$ of those with partial teeth loss, in patient group with total teeth loss only $11.6 \%$ of women had complaints of obnoxious, easily provocable pain in region of TMJ. Data of our research show that the incidence of good oral hygiene practice was $46.1 \%$. However, $28.9 \%$ of respondents have never practiced oral hygiene. Among old people`s homes patients with retained teeth satisfactory hygiene was found in $7.1 \%$ and $7.8 \%$ of cases (Fig. 1.). In group of old people with total teeth loss satisfactory oral hygiene was observed in $25.0 \%$ and $16.3 \%$ of cases, unsatisfactory in $30.0 \%$ and $14.0 \%$ of cases and medium oral hygiene was found in $45.0 \%$ and $69.8 \%$ of cases, respectively (Fig.2.). The results of our study indicate that the elderly living in old people`s homes with partial teeth loss need prosthodontical teeth replacement with removable partial dentures (RPD) in $97.6 \%$ of men and $87.5 \%$ of women. $7.1 \%$ of men and $30.0 \%$ of women had dentures but the quality of those is acceptable only in $2.4 \%$ and $9.4 \%$, respectively. $85.0 \%$ and $84.9 \%$ of all respondents with total teeth loss need prosthodontical teeth replacement. $30.0 \%$ and $19.8 \%$ of old people's homes inhabitants had total dentures but their quality was satisfactory only in $15.0 \%$ and $9.3 \%$ of cases. Our study revealed that old people becoming older lose wish to take care of their oral health and receive the dental care and lost teeth replacement (Fig.3.). It is motivated by financial pressure and overall depression.

\section{DISCUSSION}

Oral health of the examined old people living in old people's homes differs from the same age group old people`s oral health status in general population in Latvia. Such parameters as DMFT (number of decayed, missed 
and filled teeth) among old people in Latvia are higher (worse) than the same parameters in others European countries: in Germany - 22.0 (16), in Denmark - 16.7 (11), in Croatia - 27.0 (17).

In Latvia the oral health status of the elderly was studied in 1993 in the Project of ICS-2 $(2,22)$. In this research were included inhabitants of 65-74 age group. DMFT index was 24.9 (the mean number of decayed - 1.69, filled - 3.23, and missed-20.0). In the study in 2005 (3) DMFT index was 24.84 (the mean number of decayed 2.46 , filled -2.53 , and missed -19.85$)$. In our research DMFT index in inhabitants of old people`s homes was considerably higher At present, old people from old people's homes visit the dentist only for emergency extractions of teeth in cases of acute pain. No one from the examined 212 old people had intact set of teeth. The oral mucosal changes and lesions were detected in $41.9 \%$ and $50.7 \%$, respectively. The results of oral mucosal lesions studies in Latvia for the corresponding age group were not found. Results of oral mucosal researches in the world are quite different: in Germany $19.55 \%$ (18), in Hungary - 10.14\% (7), in China - 12$26 \%(8)$, in Greece $-47.0 \%$ (20), in Turkey $-40.7 \%$ (5) and in Chile $-53.0 \%$ (6). In these studies dominate angular cheilitis, hyperplasias, varices and denture stomatitis. In $57.0 \%$ of all the elderly in old people`s homes had several oral mucosal lesions. Xerostomia was found in $27.4 \%$ and $48.0 \%$ of these old people group. This quantity is close to average similar rate in corresponding age of group in Europa (52.0\%) (9, 12). The high ratio of hyposalivation and xerostomia is associated with excessive use of medication. In $1.6 \%$ of men and in $0.7 \%$ of women were found precancerous conditions (lichen planus, leukoplakia). The results of our research indicate that old people with partial teeth loss need teeth replacement in $97.6 \%$ and $87.5 \%$ of cases while the replacement of complete teeth loss is necessary in $85.0 \%$ and $84.9 \%$ of cases. The need of prosthodontic teeth replacement in Latvian population is $60.4 \%(14,15)$. Halitosis was observed in $42.9 \%$ and $39.1 \%$ of respondents with partial teeth loss and in $40.0 \%$ and $14.0 \%$ of the elderly with complete teeth loss. The mean ratio of halitosis in corresponding age group in Latvia is $33.1 \%$ (1). Evaluation of dental status of residents of old people`s homes, development and distribution of curative and preventive measures considerably will improve the quality of life in this group of residents in Latvia.

\section{CONCLUSIONS}

1. Oral health care measures for the elderly in old people's homes is insufficient, the ratio of decayed and missing teeth is high, oral hygiene mostly is unsatisfactory and many of them have halitosis.

2. The elderly from old people's homes need vast surgical and therapeutical treatment prior to prosthetics and teeth replacement. The prevalent type of prosthodontics is complete removable dentures.

3. There is need to develop the oral health care conception for the elderly living in old people`s homes in Latvia.

\section{Conflict of interest: None}

\section{REFERENCES}

1. Brinkmane A., Senakola E., Selga G. et al. Mutes veselibasstavoklanovertejumsLatvijasiedzivotajiem, izmantojot parvietojamo zobarstniecibas iekartu // RSU Zinatniskie raksti, 2004; 332 - 336

2. Care R, Urtāne I. Kariesa epidemioloǵija Latvijā no 1990. līdz 1998. gadam // AML/RSU Zinātniskie raksti, 1999; $197-201$

3. Care R, Ārne G. Kariesa intensitāte Latvijā 2005. gadā pieaugušajiem iedzīvotājiem 35-44 un 6574 gadu vecuma grupās // RSU Zinātniskie raksti, $2007 ; 340-344$

4. Comfort AO, King T, Moveni M, Tuisuva J. Dental health of Fiji institutionalized elderly // Pac Health Dialog, 2004; $11(1): 38-43$

5. Dundar N, Kal I. Oral mucosal conditions and risk factorsamong elderlyina Turkish school of dentistry // J Gerontology, 2007; 53:165 - 172

6. Espinosa I, Rojas R, Aranda W, Gamonal J. Prevalence of oral mucosal lesions in elderly people in Santiago, Chile // Oral Pathol Med J, 2003; 32(10):571- 575

7. Jahn M, Schmidt J, Fejerdy L, Tollas OL, Fejerdy $\mathrm{P}$, Madlena M. The prevalence of oral mucosal lesions in Hungary // J Fogorvosi szemle, 2007; 100: $59-63$

8. Lin HC, Cobert EF, Lo ECM. Oral mucosal lesions in adult Chinese // J of Dental Research, 2001; 80: 1486 - 1490

9. Petersen PE, Yamamoto T. Improving the oral health of older people: the approach of the WHO Global Oral Health Programme // Community Dent Oral Epidemiol, 2005; 33:81 - 92

10. Petersen PE, Krustrup U. Dental caries prevalence among adults in Denmark - the impact of sociodemographic factors and use of oral health services // Community Dental Health, 2007; 24:225 - 232

11. Putten GJ, Brand HS, Bots CP, van Nieuw Amerongen A. Prevalence of xerostomia and hyposalivation in the nursing home and the relation with member of prescribed medication // J Gerontology Geriatrics, 2003; $34: 30-36$

12. Reis SCGB, Higino MASP, Melo HMD, Freire MCM. Oral health status of institutionalized elderly in Goiânia-GO, Brazil 2003 // J Brazil epidemiology, 2005; 8: $67-73$

13. Soboleva U, Ragovska I, Pugacha I. Assessameru of the received prasthetic treatment in the Latvian population // Stomatologija, 2006; 3:36

14. Soboḷeva U, Urtāne I. Protezēšanas nepieciešamības izvērtējums Latvijas populācijā // RSU Zinātniskie raksti, $2003 ; 357-362$

15. Schiffner U, Hoffmann T, Kerschbaum T, Micheelis W. Oral health in German children, adolescents, adults and senior citizens in 2005 // Community Dental Health, 2009; 26: 18 - 22

16. Simunković SK, Boras VV, Pandurić J, Zilić IA. Oral health among institutionalised elderly in Zagreb, Croatia // Gerontology, 2005; 22:238-241

17. Splieth CH, Sumnig W, Bessel F, John U, Kocher T. Prevalence of oral mucosal lesions in a representative population // J Quintessence Int, 2007; 38:23-29 
18. Stubbs C, Riordan PJ. Dental screening of older adults living in residential aged care facilities in Perth // Aust Dent J, 2002; 47:321 - 326

19. Triantos D. Intra-oral findings and general health conditions among institutionalized and noninstitutionalized elderly in Greece // J Oral Pathol Med, 2005; 34:577 - 582

20. Unlüer S, Gökalp S, Doğan BG. Oral health status of the elderly in a residential home in Turkey // Gerodontology, 2007; 24:22 - 29

21. Urtāne I, Care R, Petersen PE. Pasaules Veselības Organizācijas starptautiskās sadarbības pētījums Latvijā 1993.g. ICS-II zị̧ojums. Rīga: 1996; $2-175$

22. Vargas CM, Yellowitz JA, Hayes KL. Oral health status of older rural adults in the United States // J Am Dent Assoc, 2003; 134:479 - 486

\section{Adress:}

Aldis Vidzis

Riga Stradins University

Department of Prosthodontics

20 Dzirciema Street,

Riga, Latvia, LV-1007

E-mail: Aldis.Vidzis@rsu.lv

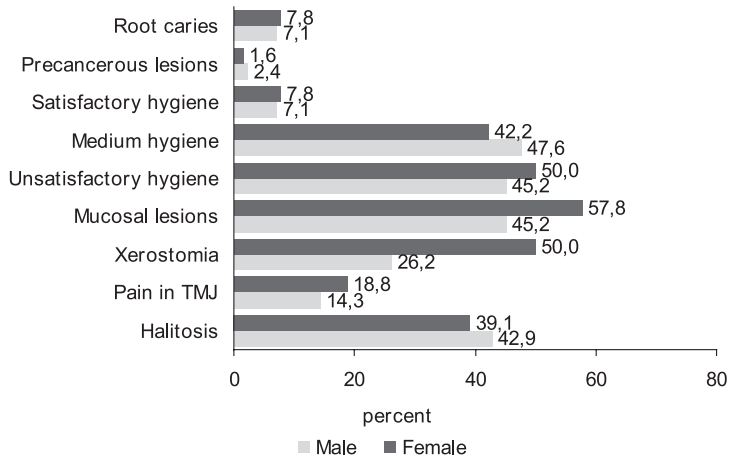

Fig. 1. The rate of clinical manifestations in respondents with partial teeth loss

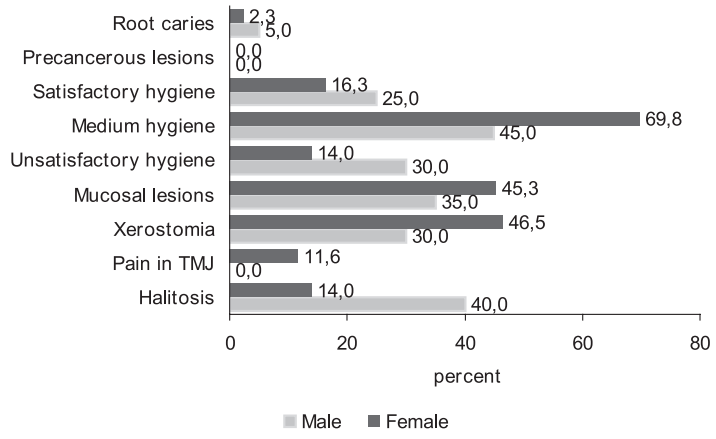

Fig. 2. The rate of clinical manifestations in respondents with complete teeth loss

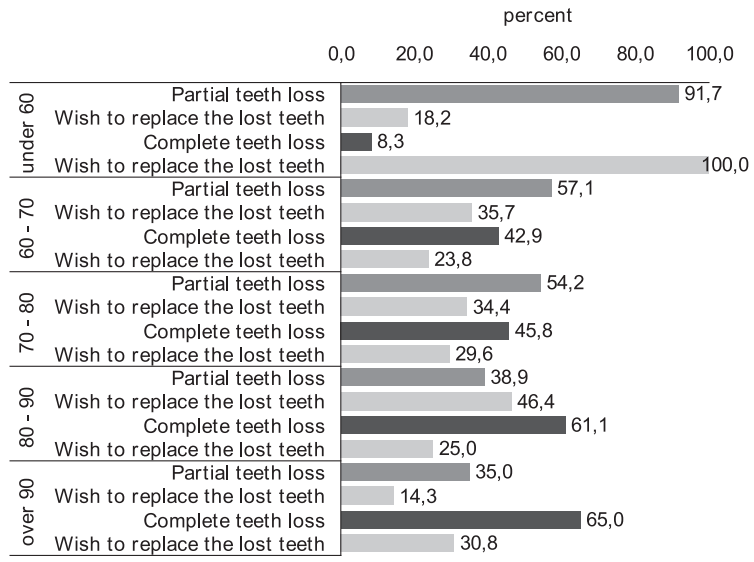

Fig. 3. Wishes of respondents to replace the lost teeth 